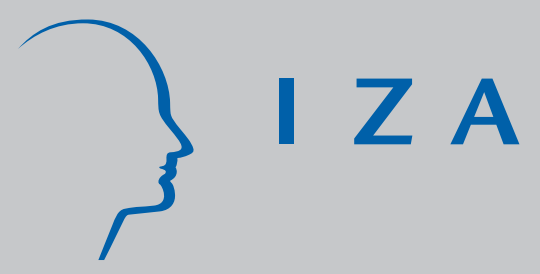

IZA DP No. 3407

How Hurricanes Affect Employment and Wages in Local Labor Markets

Ariel R. Belasen

Solomon W. Polachek

March 2008 


\title{
How Hurricanes Affect Employment and Wages in Local Labor Markets
}

\author{
Ariel R. Belasen \\ Saint Louis University \\ Solomon W. Polachek \\ State University of New York at Binghamton \\ and IZA
}

Discussion Paper No. 3407

March 2008

IZA

P.O. Box 7240

53072 Bonn

Germany

Phone: +49-228-3894-0

Fax: +49-228-3894-180

E-mail: iza@iza.org

Any opinions expressed here are those of the author(s) and not those of IZA. Research published in this series may include views on policy, but the institute itself takes no institutional policy positions.

The Institute for the Study of Labor (IZA) in Bonn is a local and virtual international research center and a place of communication between science, politics and business. IZA is an independent nonprofit organization supported by Deutsche Post World Net. The center is associated with the University of Bonn and offers a stimulating research environment through its international network, workshops and conferences, data service, project support, research visits and doctoral program. IZA engages in (i) original and internationally competitive research in all fields of labor economics, (ii) development of policy concepts, and (iii) dissemination of research results and concepts to the interested public.

IZA Discussion Papers often represent preliminary work and are circulated to encourage discussion. Citation of such a paper should account for its provisional character. A revised version may be available directly from the author. 
IZA Discussion Paper No. 3407

March 2008

\section{ABSTRACT \\ How Hurricanes Affect Employment and Wages in Local Labor Markets}

This paper adopts a generalized-difference-in-difference (GDD) technique outlined in Ariel R. Belasen and Solomon W. Polachek (IZA Discussion Paper \#2976) to examine the impact of hurricanes on the labor market. We find that earnings of the average worker in a Florida county rises over $4 \%$ within the first quarter of being hit by a major Category 4 or 5 hurricane relative to counties not hit, and rises about $1 \frac{1 / 4}{4}$ for workers in Florida counties hit by less major Category 1-3 hurricanes. Concomitantly, employment falls between $1 \frac{1}{2}$ and $5 \%$ depending on hurricane strength. On the other hand, the effects of hurricanes on neighboring counties have the opposite effects, moving earnings down between 3 and $4 \%$ in the quarter the hurricane struck. To better examine the specific shocks, we also observe sectoral employment shifts. Finally, we conduct a time-series analysis and find that over time, there is somewhat of a cobweb with earnings and employment rising and falling each quarter over a two-year time period.

JEL Classification: J23, J49, Q54, R11

Keywords: exogenous shock, difference-in-difference estimation, local labor market, earnings, employment, sectoral shifts

Corresponding author:

Ariel R. Belasen

105 Davis-Shaugnessy Hall

Saint Louis University

3674 Lindell Boulevard

St. Louis, MO 63108

USA

E-mail: abelasen@slu.edu 


\title{
How Hurricanes Affect Wages and Employment in Local Labor Markets
}

\author{
By Ariel R. Belasen and Solomon W. PolacheK*
}

Currently a growing literature is emerging on estimating the impact of exogenous shocks using Difference-in-Difference (DD) estimation. Essentially this technique compares the impact of an unexpected event in a particular locale (called the treatment/experimental group) to a location (or set of locations) called a control group, similar to the experimental group in all respects except for the shock itself. One challenge many DD studies face is how to choose the control group, and there is now a growing literature on this (Joshua A. Angrist and Alan B. Krueger, 1999; Jeffrey D. Kubik and John R. Moran, 2003; and Alberto Abadie, Alexis Diamond and Jens Hainmueller, 2007). Another challenge is whether one can generalize one's results based on one experimental group, as is typical for most DD analysis. This paper adopts a generalized-difference-in-difference (GDD) technique outlined in Ariel R. Belasen and Solomon W. Polachek (forthcoming) to examine the impact of hurricanes on the labor market. This technique incorporates many experimental as well as many control groups, and as such this approach addresses many of the shortcomings in current DD analyses. We find that earnings of the average worker in a Florida county rises over $4 \%$ within the first quarter of being hit by a major Category 4 or 5 hurricane relative to counties not hit, and rises about $1 \frac{1}{4} \%$ for workers in Florida counties hit by less major Category 1-3 hurricanes. Concomitantly, employment falls between $1 \frac{1}{2}$ and $5 \%$ depending on hurricane strength. On the other hand, the effects of hurricanes on neighboring counties have the opposite effects, moving earnings down between 3 and $4 \%$ in the quarter the hurricane struck. To better examine the specific shocks, we also

\footnotetext{
* Belasen: abelasen@slu.edu, Department of Economics, Saint Louis University, Saint Louis, Missouri 63108; Polachek: polachek@binghamton.edu, Department of Economics, State University of New York at Binghamton (Binghamton University), Binghamton, New York 13902.
} 
observe sectoral employment shifts. Finally, we conduct a time-series analysis and find that over time, there is somewhat of a cobweb with earnings and employment rising and falling each quarter over a two-year time period.

\section{Background}

The effect of hurricanes on the labor market is not obvious. According to Lucas and Rapping (1969), when people perceive a shock as having a temporary effect, they do not alter their long term perception of the economic variables that are affected by the shock. Hurricanes generally last for, at most, two or three days once they strike land. Historically speaking, even the damages from the most destructive hurricanes are typically repaired within two years of the hurricane. Therefore, one might expect to see perceptions of the future remain largely unchanged in the long run as the variables return to their steady state levels of growth.

Florida will generally witness about two hurricanes during the typical six-month hurricane season, but there are years when Florida is not hit even once. Although hurricanes are not completely unexpected shocks to the state of Florida, each hurricane event is exogenous in that the exact timing and path of a hurricane cannot be determined a priori, nor can the degree of damage unleashed. Therefore, the events can be used as an independent variable by comparing those counties that have been hit to the other counties that were not.

The hurricane data used in this analysis come from the National Hurricane Center of the National Oceanic and Atmospheric Administration (NOAA). ${ }^{1}$ The NOAA is a federal agency within the Department of Commerce that examines the conditions of the oceans and the atmosphere. In particular, the NOAA evaluates ecosystems, climatic changes, weather and water cycles, and commerce and transportation. All in all, 19 hurricanes of varying strength struck

\footnotetext{
${ }^{1}$ National Oceanic and Atmospheric Administration, http://www.noaa.gov/
} 
Florida in the 18 year period between 1988 and 2005. To coincide with this time period, quarterly employment ${ }^{2}$ and average quarterly earnings data from the Bureau of Labor Statistics (BLS) Quarterly Census of Employment and Wages (QCEW) ${ }^{3}$ were used, spanning the time period starting with the first quarter of 1988 and continuing through the fourth quarter of $2005 .{ }^{4}$ The BLS surveys employers regarding their total wage bill and employment each quarter. We use these data for each county.

\section{The GDD Estimation Model}

The GDD model begins in similar fashion to the DD model in the sense that it compares outcome $Y$ (actually, in our case two outcomes, employment denoted as $N$ and earnings denoted as $y$ ) between treatment groups $(H)$ and control groups $(\tilde{H})$. Thus for event $H$ (in our case a hurricane) there are two possible outcomes $Y_{H}$ if a hurricane occurs and $Y_{\widetilde{H}}$ if it does not. Let $E\left[Y_{c t} \mid \tilde{H}\right]$ represent the expected value of $Y$ if a hurricane does not occur in Florida county c at time t, and let $E\left[Y_{c t} \mid H\right]$ be the expected value if the event does occur in county c at time t. Following Angrist and Krueger's (1999) specification, ${ }^{5}$ the conditional means take the following form:

$$
\begin{aligned}
& E\left[Y_{c, t} \mid \tilde{H}\right]=\beta_{c}+\beta_{t} \\
& E\left[Y_{c, t} \mid H\right]=E\left[Y_{c, t} \mid \tilde{H}\right]+\delta^{*}
\end{aligned}
$$

The parameter $\delta^{*}$ measures the exogenous shock when the two equations are differenced:

\footnotetext{
${ }^{2}$ Some employment data were available in a monthly format as well, and whenever possible, monthly data were used for employment.

${ }^{3}$ Bureau of Labor Statistics, http://www.bls.gov/

${ }^{4}$ Hourly employment data would be preferable for this study, however, due to data limitations, total employment numbers were used instead.

${ }^{5}$ See Angrist and Krueger (1999) equations (18) and (19).
} 


$$
E\left[Y_{c, t} \mid H\right]-E\left[Y_{c, t} \mid \tilde{H}\right]=\delta^{*}=\delta_{c}+\delta_{t}
$$

This $\delta^{*}$ difference effectively becomes the time and event averaged exogenous shock resulting from the set of events $\boldsymbol{H}$, taking into account characteristics of the counties hit. As such, it is composed of two parts: $\delta_{c}$ is the county specific effect of hurricanes and $\delta_{t}$ is the time-varying effect of hurricanes. Both are identified in the GDD given that c indexes each of the 67 Florida counties and that data on H entails all 19 hurricanes hitting Florida between 1988 and 2005. ${ }^{6}$ As will be illustrated in the next section, we use equation (3) in three ways: First, in model (4) and (5), to get at the overall effect of $H$; second, in model (6) and (7) which represent a disaggregated version of (4) and (5) to get at $H$ 's effects by industry; and third, in model (8) and (9) to get at lagged effects of $H$.

\section{Application of the model}

The study examines county-level employment (which we denote as $\mathrm{N}$ ) as well as countylevel average quarterly earnings per worker (which we denote as y) in the state of Florida. In order to measure the actual effects of hurricanes on employment and earnings, we control for additional factors that affect each county. Because Florida’s economy has been growing rapidly over the last half-century, and every county in Florida has benefited from this growth, we control for the state trends of Florida by using GDD analysis to compare the average county impacted by a hurricane to the average unaffected county.

\footnotetext{
${ }^{6}$ Hurricanes are categorized according to the Saffir-Simpson Scale based on their wind speed. Hurricanes Florence, Allison, Erin, Danny, Earl, Irene, Gordon, Ophelia and even the Floridian part of Katrina were category one hurricanes at landfall, meaning they had wind speeds ranging between 74 and 95 miles per hour. Hurricanes Georges, Frances, and Rita were category two hurricanes and had wind speeds ranging between 96 and 110 miles per hour. With wind speeds ranging between 111 and 130 miles per hour, Hurricanes Opal, Ivan, Jeanne, and Dennis were classified as category three hurricanes. Hurricane Charley reached 150 miles per hour and became category four as it hit the mainland. Hurricanes Andrew and Wilma were category five hurricanes and had winds well above 180 miles per hour.
} 
To get at the effects of hurricanes, we incorporate hurricane severity as well as hurricane location, particularly whether a county experienced a direct hurricane hit or was a neighboring county to one that was hit directly. In doing so, we split up the hurricanes into two subcategories based on the Saffir-Simpson Scale. Hurricanes which fall into categories 1, 2, or 3 made up the low intensity group (SS1), and hurricanes in categories 4 or 5 were placed into the high intensity group (SS2). These variables now replace the hurricane variable $(H)$ in the initial model. Thus the model takes the following form, where SS1 and SS2 correspond to the two Saffir-Simpson groups, $D$ refers to a directly hit county, $I$ refers to a neighboring county, and variable $X$ refers to whether the event occurred during the summer season:

$$
\begin{aligned}
& \left(\Delta \ln N_{c t}-\Delta \ln N_{t}\right)=\delta_{11} \Delta S S 1_{c t}^{D}+\delta_{12} \Delta S S 2_{c t}^{D}+\delta_{13} \Delta S S 1_{c j t}^{I}+\delta_{14} \Delta S S 2_{c t}^{I}+\alpha_{1} X_{c}+\varepsilon_{c t} \\
& \left(\Delta \ln y_{c t}-\Delta \ln y_{t}\right)=\delta_{21} \Delta S S 1_{c t}^{D}+\delta_{22} \Delta S S 2_{c t}^{D}+\delta_{23} \Delta S S 1_{c t}^{I}+\delta_{24} \Delta S S 2_{c t}^{I}+\alpha_{2} X_{c}+\varepsilon_{c t}
\end{aligned}
$$

Table 1 outlines the results of these regressions. High intensity hurricanes have a much greater impact on earnings than the lower intensity hurricanes, as they boost the growth rate of earnings per worker by $4.35 \%$ on average relative to workers in the average county. There is also a greater magnitude effect on employment, as it drops by $4.76 \%$ on average relative to the average county. Meanwhile, counties that neighbor the directly hit county will not face an effect on employment from the high intensity hurricanes, but will experience a $3.33 \%$ decline in average wage growth relative to the typical county. Low intensity hurricanes, on the other hand, will relatively decrease employment by just $1.47 \%$ and boost earnings growth by $1.28 \%$ on average in directly hit counties. In neighboring counties, they will decrease to the average earnings growth rate by $4.51 \%$. 
Table 1: GDD Regression Results of Hurricanes on Change in the Average Growth Rate of Earnings and Employment in Hurricane Stricken Counties Relative to other Counties

\begin{tabular}{|c|c|c|c|c|}
\hline & \multicolumn{2}{|c|}{ Direct Effect } & \multicolumn{2}{c|}{ Neighboring Effect } \\
\hline Hurricane Strength & Employment & Earnings & Employment & Earnings \\
\hline Category 1-3 & $-0.0147^{* * *}$ & $0.0128^{* *}$ & 0.0023 & $-0.0451^{* * *}$ \\
Category 4-5 & $-0.0476^{* * *}$ & $0.0435^{* * *}$ & 0.0079 & $-0.0333^{* * *}$ \\
\hline
\end{tabular}

Note: Table reports selected coefficients of equations (4) and (5) fit with QCEW data. Other variables include a seasonal adjustment variable. See text for details.

*Significant at the $10 \%$ level; **Significant at the $5 \%$ level; ***Significant at the $1 \%$ level

Second, we disaggregate (3) to subdivide the employment and earnings data across each industrial sector (Table 2). Equations (6) and (7) reflect the sector-specific effects of hurricanes, where $S$ represents one of the five sectors of the labor market:

$$
\left(\Delta \ln N_{c t}^{S}-\Delta \ln N_{t}^{S}\right)=\delta_{11} H_{c t}^{D}+\delta_{12} \Delta H_{c t}^{N}+\alpha_{1} X_{c}+\varepsilon_{c t}
$$

$$
\left(\Delta \ln y_{c t}^{S}-\Delta \ln y_{t}^{S}\right)=\delta_{21} H_{c t}^{D}+\delta_{22} \Delta H_{c t}^{N}+\alpha_{2} X_{c}+\varepsilon_{c t}
$$

Each industrial sector responds slightly differently from the aggregate model, though the weighted average of growth in employment and earnings appears to be about the same. Specifically we find that employment and earnings move in the same direction for each of the industrial sectors, indicating that the hurricanes likely trigger demand shocks in the labor markets of directly hit counties. The construction and service sectors are positively shocked while the manufacturing; trade, transportation, and utility (TTU); and finance, investment, and real estate (FIRE) are shocked downward. In neighboring counties, we find significantly negative effects on earnings in the service and TTU sectors - also corresponding well to the aggregate model. 
Table 2: GDD Regression Results of Hurricanes on Change in the Average Growth Rate of Earnings and Employment in Hurricane Stricken Counties Relative to other Counties by Industry

\begin{tabular}{|l|c|c|c|c|}
\hline Industrial Sector & \multicolumn{2}{|c|}{ Direct Effect } & \multicolumn{2}{c|}{ Neighboring Effect } \\
\hline & Employment & Earnings & Employment & Earnings \\
\hline Construction & 0.0350 & $0.0463 * * *$ & -0.0039 & -0.0228 \\
Manufacturing & -0.0031 & $-0.0264^{*}$ & 0.0099 & -0.0031 \\
Trade, Transportation, and Utilities & $-0.0679 *$ & $-0.0279 * * *$ & 0.0061 & $-0.0083^{* * *}$ \\
Service & $0.0846 *$ & $0.0457 * * *$ & -0.0039 & $-0.0044^{*}$ \\
Finance, Investment, Real Estate & -0.0041 & $-0.0849 * * *$ & 0.0038 & -0.0029 \\
\hline
\end{tabular}

Note: Table reports selected coefficients of equations (6) and (7) fit with QCEW data. Other variables include a seasonal adjustment variable. See text for details.

*Significant at the $10 \%$ level; $* *$ Significant at the $5 \%$ level; ***Significant at the $1 \%$ level

The differences between the individual sectors and the aggregate labor market appear to be driven by the heterogeneity of the county-level labor market. Certain counties are more agrarian and thus are less likely to be affected in the way that heavily industrialized counties are affected. Furthermore, as Belasen and Polachek (forthcoming) show, the Florida Panhandle is affected much differently than the rest of the state due to a major focus on the service sector in that region. When one accounts for the differences across counties, it becomes much more apparent that the individual demand shocks are in fact representative of the aggregate effect we find in which earnings rise and employment falls.

For the third application of equation (3), we respecify the model to examine the lingering effects of hurricanes over time. Vector $\vec{H}^{D}=\left(H_{c t}^{D}, H_{c t-1}^{D}, H_{c t-2}^{D}, \ldots\right)$ is used to represent the series of effects occurring when a hurricane directly strikes a county. Subscript $c$ indicates that the hurricane is directly affecting county $c$, and the lag indicates how far back in time the hurricane hit:

$$
\begin{aligned}
& \left(\Delta \ln N_{c t}-\Delta \ln N_{t}\right)=\Delta \vec{H}_{c t}^{D} \vec{\delta}_{1}+\alpha_{1} X_{c}+\varepsilon_{c t} \\
& \left(\Delta \ln y_{c t}-\Delta \ln y_{t}\right)=\Delta \vec{H}_{c t}^{D} \vec{\delta}_{2}+\alpha_{2} X_{c}+\varepsilon_{c t}
\end{aligned}
$$


Figure 1 shows the regression results of a hurricane's effects in time $t$ as well as the lingering effects of that hurricane for 24 months following the storm. ${ }^{7}$ As can be seen, a hurricane will immediately boost growth in earnings in the counties where it strikes followed by an immediate downturn three months (one quarter) later. As time goes by, earnings growth will continue to follow this pattern before settling in at a new steady state level roughly $0.40 \%$ above the level of growth for an average county. We find that the labor market takes a cobweb form in which employment jumps about a year after the hurricane (coinciding with a decrease in earnings) and then decreases as earnings increase before settling at a growth rate $4.32 \%$ lower than that of unaffected counties.

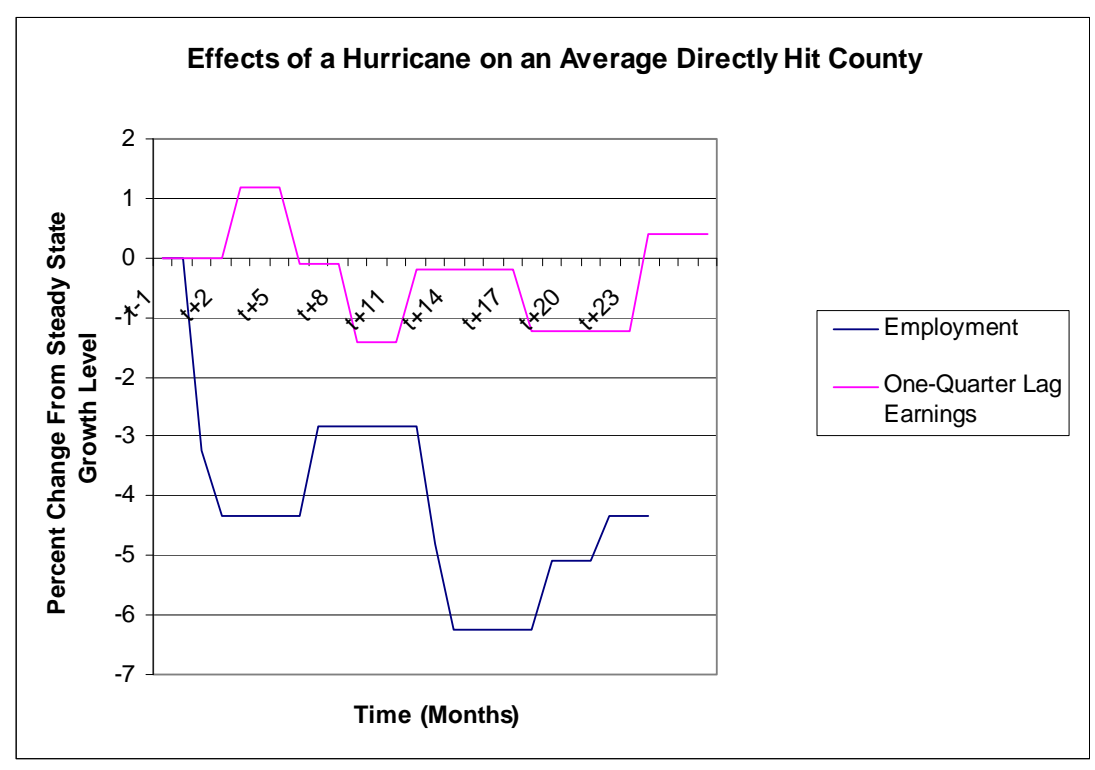

Figure 1: Effects of a Hurricane on an Average Directly Hit County over a 24 Month Duration

While this in no way indicates that earnings growth in a hurricane stricken county will permanently remain higher, nor that employment growth will remain permanently lower, than in a county that has avoided the hurricane, it does imply that the temporary wage gains may not be as short term as the ones Paulo Guimaraes, Frank L. Hefner, and Douglas P. Woodward (1993)

\footnotetext{
${ }^{7} \mathrm{~A}$ table of the regression results is available upon request.
} 
reported based on Hurricane Hugo. On the other hand, these findings are consistent with the existing literature of Bradley T. Ewing and Jamie B. Kruse (2006) and Ewing, Kruse, and Mark L. Thompson (2007) which found that after a hurricane, earnings will jump immediately and then converge back towards pre-hurricane levels. Additionally, they find that while hurricanes create an economic disturbance in the short run, oftentimes they can lead to economic gains in the long run, just as we have found in this paper.

\section{Conclusion}

By using a GDD approach to compare changes in employment and earnings between counties hit and not hit by all nineteen (1988-2005) Florida hurricanes, we examine how hurricanes affect the Florida labor market. Overall we find that employment decreases by as much as $4.76 \%$ and earnings rise by up to $4.35 \%$ in counties directly hit, whereas neighboring counties face a decrease in earnings up to $4.5 \%$ on average. As expected, more severe the hurricanes have the largest effects. A micro study of five industrial sectors comprising the bulk of Florida's labor market reveals that hurricanes lead to demand shocks in the labor market, with the net results corresponding to the aggregate labor market effects. Over time, counties hit by hurricanes experience a positive net effect on earnings and a negative net effect on employment, but that these effects dissipate over time. Whereas we apply the GDD technique to hurricanes, the approach is applicable to analyzing a wider range of exogenous shocks such as earthquakes, tornadoes, tsunamis, and more. 


\section{References:}

Abadie, Alberto, Alexis Diamond, and Jens Hainmueller. 2007. "Synthetic Control Methods for Comparative Case Studies: Estimating the Effect of California’s Tobacco Control Problem,” unpublished working paper.

Angrist, Joshua A. and Alan B. Krueger. 1999. “Empirical Strategies in Labor Economics,” in Orley C. Ashenfelter, and David A. Card,. editors, Handbook of Labor Economics, 3A, Amsterdam: Elsevier, 1277-1366.

Belasen, Ariel R. and Solomon W. Polachek. forthcoming. "How Disasters Affect Local Labor Markets: The Impact of Hurricanes in Florida,” Journal of Human Resources.

Card, David. 1990. “The Impact of the Mariel Boatlift on the Miami Labor Market,” Industrial and Labor Relations Review, 43 (2), 245-257.

Ewing, Bradley T., and Jamie B. Kruse. 2006. “Hurricanes and Unemployment,” Natural Hazards Review.

Ewing, Bradley T., Jamie B. Kruse, and Mark A. Thompson. 2007. “Twister! Employment Responses to the May 3, 1999, Oklahoma City Tornado,” Journal of Applied Economics.

Guimaraes, Paulo, Frank L. Hefner, and Douglas P. Woodward. 1993. "Wealth and Income Effects of Natural Disasters: An Econometric Analysis of Hurricane Hugo.” The Review of Regional Studies 23: 97-114.

Kubik, Jeffrey D. and John R. Moran. 2003. “Can Policy Changes be Treated as Natural Experiments? Evidence from Cigarette Excise Taxes,” SSRN Working Paper 269609.

Lucas, Robert and Rapping, Leonard. 1969. "Price Expectations and the Phillips Curve,” American Economic Review, 59 (3), 342-350. 